\title{
Avaliação do alongamento passivo e da eletroestimulação sobre a plasticidade muscular
}

\author{
Evaluation of passive stretching and electrostimulation on muscle plasticity
}

\section{Evaluación de estiramientos pasivos y electroestimulación sobre plasticidad muscular}

\author{
Eliane Ferreira Marinho1*, Priscila Mickelly Araújo Neves, Emanuele Ferreira Marinho², Daliane \\ Ferreira Marinho ${ }^{3}$, Adriana Caroprezo Morini ${ }^{4}$.
}

\section{RESUMO}

Objetivo: Avaliar e comparar efeitos macro e microscópicos das terapias de alongamento e eletroestimulação sobre o tecido muscular após imobilização. Métodos: Utilizados 25 ratos (Rattus norvegicus albinus, linhagem wistar) machos adultos, sadios, divididos aleatoriamente em cinco grupos $(n=5)$. Foram imobilizados por 7 dias, depois receberam 10 sessões de alongamento passivo e eletroestimulação muscular, de forma isolada e combinada, no músculo tibial anterior direito, que após foi extraído para análise. Variáveis macroscópicas: massa e comprimento total do músculo, variáveis microscópicas: número de sarcômeros em série e tecido conjuntivo. Dados analisados de forma cega, armazenados e tratados por estatística descritiva através do Software Bioestatic 5.3. Resultados: Massa muscular: não se observou ganho sobrepujante à perda pela imobilização, mas conteve-se perda maior com a utilização da eletroestimulação de forma isolada. Número de sarcômeros em série: alongamento e eletroestimulação foram eficientes para o aumento, a combinação das terapias não interferiu negativamente no tratamento. Comprimento do músculo e quantidade de tecido conjuntivo depositado no meio intramuscular: resultados estatísticos insignificantes. Conclusão: Eletroestimulação é mais eficiente em conter a perda de massa muscular, ambas técnicas de forma isolada são benéficas para aumento do número de sarcômeros.

Palavras-chave: Músculo, Plasticidade, Alongamento, Eletroestimulação.

\section{ABSTRACT}

Objective: To evaluate and compare macro and microscopic effects of stretching and electrostimulation therapies on muscle tissue after immobilization. Methods: 25 healthy male rats (Rattus norvegicus albinus, lineage) were used, randomly divided into five groups $(n=5)$. They were immobilized for 7 days, then received 10 sessions of passive stretching and muscle electrostimulation, in an isolated and combined way, in the right anterior tibial muscle, which afterwards was extracted for analysis. Macroscopic variables: total muscle mass and length, microscopic variables: number of sarcomeres in series and connective tissue. Data analyzed blindly, stored and treated by descriptive statistics using the Bioestatic 5.3 Software. Results: Muscle mass: there was no gain surpassing the loss due to immobilization, but greater loss was contained with the use of electrostimulation in isolation. Number of sarcomeres in series: stretching and electrostimulation were efficient for the increase, the combination of therapies did not interfere negatively in the treatment. Muscle length and amount of connective tissue deposited in the intramuscular environment: insignificant statistical results. Conclusion: Electrostimulation is more efficient in containing the loss of muscle mass, both techniques in isolation are beneficial for increasing the number of sarcomeres.

Keywords: Muscle, Plasticity, Stretching, Electrostimulation.

\section{RESUMEN}

Objetivo: Evaluar y comparar los efectos macro y microscópicos de las terapias de estiramiento y electroestimulación sobre el tejido muscular después de la inmovilización. Métodos: Se usaron 25 ratas macho sanas (Rattus norvegicus albinus, linaje), divididas aleatoriamente en cinco grupos $(n=5)$. Estuvieron inmovilizados durante 7 días, luego recibieron 10 sesiones de estiramiento pasivo y electroestimulación

${ }^{1}$ Centro Universitário da Amazônia (UNAMA), Santarém - PA, *E-mail: eliane.marinho@unama.br

2 Universidade do Estado do Pará (UEPA), Castanhal - PA.

3 Universidade do Estado do Pará (UEPA), Santarém - PA.

${ }^{4}$ Universidade Federal do Oeste do Pará (UFOPA), Santarém - PA. 
muscular, de forma aislada y combinada, en el músculo tibial anterior derecho, que luego se extrajo para su análisis. Variables macroscópicas: masa muscular total y longitud, variables microscópicas: número de sarcómeros en serie y tejido conectivo. Datos analizados a ciegas, almacenados y tratados mediante estadísticas descriptivas utilizando el software Bioestatic 5.3. Resultados: Masa muscular: no hubo ganancia que supere la pérdida debido a la inmovilización, pero se contuvo una mayor pérdida con el uso de electroestimulación en forma aislada. Número de serie de sarcómeros: el estiramiento y la electroestimulación fueron eficientes para el aumento, la combinación de terapias no interfirió negativamente en el tratamiento. Longitud muscular y cantidad de tejido conectivo depositado en el entorno intramuscular: resultados estadísticos insignificantes. Conclusión: La electroestimulación es más eficiente para contener la pérdida de masa muscular, ambas técnicas aisladas son beneficiosas para aumentar el número de sarcómeros.

Palabras clave: Músculo, Plasticidad, Estiramiento, Electroestimulación.

\section{INTRODUÇÃO}

A imobilidade caracteriza-se pela perda de capacidade funcional, pela supressão dos movimentos articulares, pela incapacidade de mudança postural, na maioria das vezes decorrente de doenças crônicodegenerativas, doenças agudas graves, incapacidade ou inatividade (FERNANDES F, et al., 2011).

O movimento humano, como condição fundamental para qualidade de vida, vem sendo amplamente estudado ao longo das últimas décadas. As adaptações musculares, suas implicações no organismo e os recursos utilizados para manter ou recuperar a função muscular normal, são o cerne de pesquisas das diversas áreas. Isto decorre da importância que o movimento tem no desenvolvimento das funções adequadas do indivíduo, e quando na falta dele, das inúmeras e severas repercussões patológicas infligidas ao organismo. Assim, a ciência se esforça na busca incessante e necessária pela compreensão dos processos de adaptação decorrentes do uso, das restrições ou imobilizações físicas, bem como das intervenções terapêuticas efetivas, embasadas em evidências que apontem eficácia e segurança para a prática clínica (FERNANDES F, et al., 2011; KHAJURIA DK, et al., 2014; MACEDO ACB, et al., 2016; SALVINI TF, et al., 2012).

Em relação especificamente aos músculos, é notória a capacidade deste de se adaptar às diferentes situações, alongando-se, encurtando e sofrendo alterações plásticas. A ciência já afiançou o entendimento sobre a capacidade do músculo de sofrer alterações como adição ou remoção de sarcômeros em série, o que irá determinar o tamanho longitudinal do músculo e a geração de força, assim como também alterações estruturais nos tecidos conjuntivos causando o aumento da rigidez e diminuição da extensibilidade do tecido. $E$ as alterações estão frequentemente associadas ao uso ou desuso das estruturas (AIRES MM, 2018; MOORE KL, 2018).

Temos adaptações sempre como resposta dos músculos às novas demandas, como a imobilização ou o desuso, ou a prática de atividade física, na tentativa de manter a homeostase e condições ideias de atividade. Entre os efeitos deletérios observáveis, gerados após longos períodos de imobilização, podemos citar diuturnamente a atrofia muscular, mudança estrutural nos tecidos conjuntivos, com aumento na rigidez levando a diminuição da extensibilidade do tecido, variações de comprimento muscular devido à alteração do número e tamanho de sarcômeros em série, e a diminuição da força (KODAMA FY, et al , 2012; MARQUES AP, 2005; SALVINI TF, 2012; TABARY JC, et al., 1972).

Para amenização dos efeitos nocivos do desuso, costuma-se utilizar técnicas de alongamento e eletroestimulação nos protocolos de tratamento fisioterapêutico, com o intuito de prevenir e recuperar o trofismo e a flexibilidade muscular, garantindo a funcionalidade do segmento corporal. Estas técnicas são amplamente pesquisadas de forma isolada, em protocolos diversos de tratamento. Tais estudos objetivam, em geral, entender os mecanismos que levam às adaptações musculares após o uso desses recursos, que assim justifiquem suas aplicações na prática clínica (FERNANDES F, et al., 2011; KODAMA FY, et al., 2012; OSAKI GAT, et al., 2014).

Os efeitos da técnica de alongamento, de forma isolada, são conhecidos como sendo capazes de promover a adição de sarcômeros em série e consequente, o aumento longitudinal do músculo, favorecendo a recuperação da extensibilidade muscular normal. Existem técnicas e formas variadas de promover 
alongamento muscular, ainda sem um consenso para sua aplicação quanto a escolha da técnica ideal, pois existem dúvidas quanto a duração e o número de séries necessárias para atingir a máxima eficiência, e talvez até mesmo por esse motivo seja um tema recorrentemente discutido no meio acadêmico (WILLIAMS PE, et al., 1988; GOLDSPINK G, et al., 2002; MASSENZ KJV, 2019).

Quanto à eletroestimulação, sua capacidade de frear a atrofia muscular se dá por predispor a diminuição da deposição de tecido conjuntivo no meio intramuscular, que ocorre devido ao estímulo de contração muscular contínua e prolongada. No entanto, sua aplicação também age na deleção de sarcômeros em série, o que seria nos casos de encurtamento, um efeito adverso, predispondo a diminuição da fibra muscular em sentido longitudinal. Tais condições são antagônicas quando se pensa no objetivo do tratamento após imobilização, que seria o de manter e recuperar o comprimento muscular. E são justamente por motivos como estes, que se fazem necessários estudos contínuos que respondam tais questionamentos (MARQUES AP, 2005; POLONIO JT, et al. 2010; SALVINI TF, et al., 2012).

Em relação aos estudos existentes na literatura atual quanto a utilização dessas técnicas na recuperação muscular, elas são usualmente testadas separadamente. Os estudos sobre a eletroestimulação são bastante aplicados durante os períodos de imobilização, e os com alongamentos são usados após este período. Essa realidade científica não reproduz, no entanto, a prática clínica, onde normalmente se utilizam as terapias em conjunto e após o período de imobilização (DURIGAN JLQ, 2008; FERNANDES F, et al.,2011; KODAMA FY, et al., 2012).

Nesse sentido, o presente estudo, de forma experimental em ratos, visou reproduzir a prática clínica do fisioterapeuta, onde após uma situação induzida de imobilização foram aplicadas as técnicas de alongamento estático passivo manual e a estimulação elétrica neurofuncional, de forma isolada e combinadas, para assim avaliar os efeitos destas intervenções sobre o músculo. Como variáveis de interesse foram selecionados: 0 comprimento e a massa muscular, o número de sarcômeros em série e a deposição de tecido conjuntivo intramuscular (KIRSCH RF, et al., 1985; WILLIAMS PE, et al., 1988). Dessa forma, o objetivo principal foi avaliar e comparar os efeitos macro e microscópicos das terapias de alongamento e eletroestimulação sobre o tecido muscular, após período de imobilização.

\section{MÉTODOS}

Para esta pesquisa foram utilizados 25 ratos da espécie Rattus norvegicus albinus e da linhagem Wistar, todos machos adultos, sadios, com idade superior a 90 dias e peso entre 250 e 300 gramas. Durante o período da pesquisa estes animais foram mantidos em gaiolas apropriadas de polipropileno com medidas de $41 \mathrm{~cm} \times 34 \mathrm{~cm} \times 16 \mathrm{~cm}$, forradas com maravalha, acomodando até cinco animais em cada um destes microambientes, em condições ambientais controladas ( 12 horas de ciclo claro/escuro; ambiente higienizado; temperatura de $22 \pm 2^{\circ} \mathrm{C}$ e ventilação adequada), além da oferta de alimento e água ad libitum aos animais durante todo o experimento, conforme normas do Colégio Brasileiro de Experimentação Animal (COBEA). O projeto de pesquisa foi aprovado pelo Comitê de Ética no uso de animais da Universidade Federal do Oeste do Pará (CEUA) sob o número de protocolo 09014-2016.

Para esta pesquisa os animais foram divididos de forma aleatória em cinco grupos $(n=5)$ : 1 . Grupo controle negativo (GC), que não foi submetido a qualquer intervenção; 2. Grupo controle positivo, apenas imobilizado por 7 dias (GI7); 3. Grupo imobilizado por 7 dias e tratado com alongamento por 10 dias (GI7+AL); 4. Grupo imobilizado por 7 dias e tratado com eletroestimulação por 10 dias (Gl7+EE); 5. Grupo imobilizado por 7 dias e tratado com alongamento e eletroestimulação por 10 dias (GI7+AL+EE);

A técnica de indução anestésica empregada foi o método de injeção intraperitoneal de quetamina $(0,10 \mathrm{ml} / 100 \mathrm{~g})$ e xilazina $(0,25 \mathrm{ml} / 100 \mathrm{mg})$. O membro imobilizado foi o posterior direito, submetendo o músculo tibial anterior ao desuso em posição próxima à anatômica.

A imobilização empregada foi similar a descrita por Khajuria DK, et al. (2014), com adaptações após testes. Sendo que a imobilização permitia que o animal deambulasse sobre três patas. $O$ molde foi aberto após quatro dias de imobilização, para que se pudesse observar o estado da pele, fechado e reaberto quando 
completados os sete dias. Os tratamentos iniciaram um dia após a retirada das imobilizações e seguiram por 10 dias consecutivos, com a realização de alongamento e eletroestimulação de forma isolada, e alongamento mais eletroestimulação de forma combinada, de acordo com os grupos.

A técnica de alongamento escolhida foi o manual passivo e estático, onde um pesquisador conteve o animal enquanto o outro manteve a pata em extensão, com dorsiflexão total e leve inversão de tornozelo, aplicando uma força subjetiva, não quantificada, capaz de mover a articulação a um pouco além da amplitude observada para o segmento, sustentada em 1 (uma) série de 30 (trinta) segundos, ao longo de 10 (dez) dias consecutivos, uma vez ao dia (CARVALHO LC, et al., 2008; MARQUES AP, 2005; ROSÁRIO JLR, et al., 2004).

A Eletroestimulação Neuromuscular foi aplicada utilizando-se um aparelho gerador de corrente elétrica, Neurodyn III®, da marca IBRAMED®, devidamente calibrado, transmitida ao animal através de cabos e eletrodos faciais (carbono-silicon) autoadesivos, recortados no tamanho apropriado para a pata do animal, acoplados diretamente à pele previamente tricotomizada. A corrente empregada foi de baixa frequência, com parâmetros de $30 \mathrm{~Hz}$ de frequência (f), $300 \mu \mathrm{s}$ de duração de impulso (t) de ondas bifásicas, com terapia tendo duração de 10 minutos, uma sessão diária, ao longo de 10 dias (AGNE JE, 2005; MATHEUS JPC, et al., 2007; POLONIO JT, et al., 2010).

Para a aplicação da eletroterapia, os animais foram contidos através de faixa retangular de material isopor/plástico maleável, envolvendo o animal e fixando com molde em tecido, amarrando as pontas, de forma que permanecesse imóvel pelo tempo da aplicação da terapia, sem promover desconforto ao animal. $O$ membro a ser tratado foi deixado exposto para receber a terapia (Figura 1). Após o $7^{\circ}$ dia foram retiradas as imobilizações, e 24 horas após a retirada destas os animais do Gl7 (controle positivo) seguiram para eutanásia, e os animas dos grupos de tratamento iniciaram estes, o que durou dez dias consecutivos. Após 24 horas do término das terapias os animais tratados também seguiram para a eutanásia.

A eutanásia ocorreu por superdose de anestésicos. O músculo tibial anterior do membro inferior direito de cada animal foi extraído e seguiram os preparos conforme descrito por Williams PE e Goldspink G (1971). O músculo tibial anterior foi dividido em duas porções de forma longitudinal, uma parte recebeu banho de 3 horas no glutaraldeído à $2,5 \%$, depois banho em $\mathrm{HNO}_{3}$ (ácido nítrico) por 48 horas e foram armazenadas em glicerol $50 \%$. A segunda parte foi imediatamente armazenada em formol a $10 \%$.

Figura 1 - a. Detalhe da forma de contenção e do comportamento dos animais; b. Animal preparado para receber a terapia por eletroestimulação.

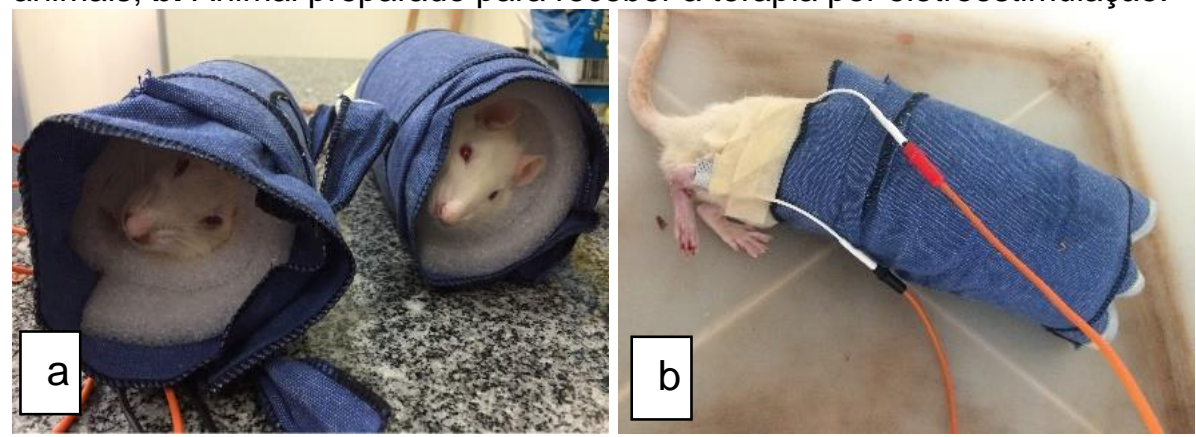

Fonte: Marinho EF, et al., 2018.

Com os músculos extraídos foram confeccionadas lâminas para as variáveis propostas, similar ao descrito por Macedo ACB, et al. (2016). Das porções armazenadas em formol a 10\% foram preparadas lâminas histológicas coradas com Pricosirius Red. Das porções armazenadas em glicerol foram separadas fibras musculares, depositadas em lâminas para serem fotomicrografadas. As lâminas foram fotomicrografadas por câmera acoplada ao microscópio óptico BX-41 Olympus®.

A análise histopatológica iniciou com a verificação da coloração e consistência do músculo, na sequência foi mensurada a massa e o comprimento no momento da eutanásia. A análise por microscopia óptica avaliou o número de sarcômeros em série e a quantidade de tecido conjuntivo depositado no meio intramuscular. 
As fotomicrografias das lâminas histológicas coradas com Sirius Red foram realizadas por meio de microscopia óptica no BX-41 Olympus ${ }^{\circledR}$, com objetiva de $20 x$ e analisadas de forma subjetiva, com a identificação visual da quantidade de tecido corado em vermelho (perimísio e endomísio) (Figura 2). A avaliação foi realizada de forma cega por um pesquisador externo que atribuiu valores de 1 a 3 cruzes $(+,++$, $+++)$, de acordo com a presença da coloração, sendo considerada a média do grupo para a análise estatística comparativa.

Figura 2 - Lâminas histológicas do músculo tibial anterior em corte transversal, corados com Sirius Red, fotomicrografados em microscopia óptica, com objetiva de 20x, a ser analisadas de forma cega e subjetiva. Demonstrando as estruturas a serem analisadas.

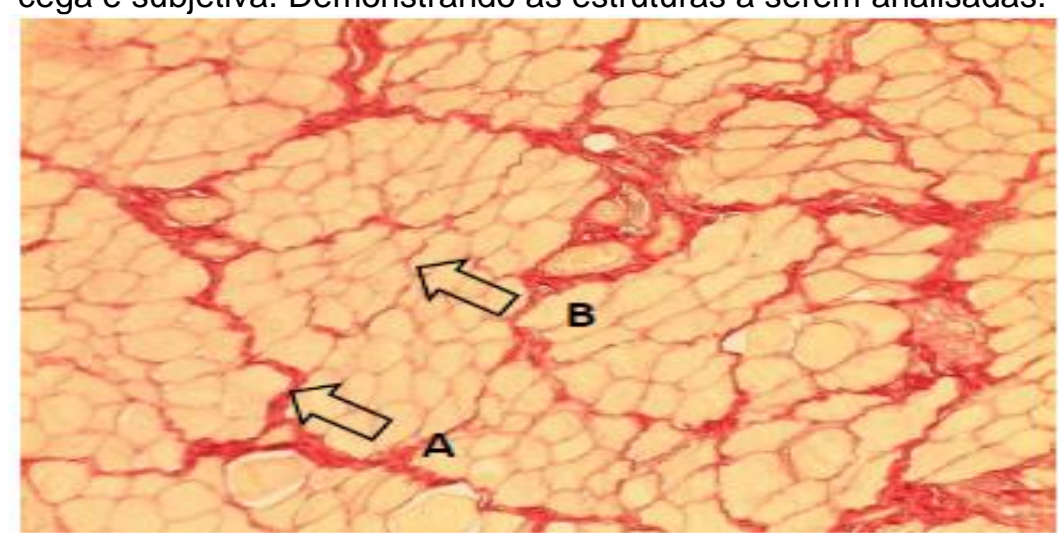

Legenda: (A) Perimísio, (B) Endomísio.

Fonte: Marinho EF, et al., 2018.

Os músculos para contagem de sarcômeros foram fixados em glicerol, tiveram três de suas fibras separadas e observadas em lâmina em microscópio óptico BX-41 Olympus, na objetiva de 50x. As imagens foram calibradas, aplicando-se a régua de $100 \mu \mathrm{m}$, fotomicrografadas e posteriormente a quantidade de sarcômeros foi contada manualmente ao longo deste intervalo, em cada fibra. Foi realizada a média de sarcômeros para cada amostra a partir das três fibras, e o número total de sarcômeros foi estimado seguindo a equação: tamanho do músculo no momento da eutanásia, dividido por cem, multiplicado pela média de sarcômeros do intervalo, conforme exemplo apresentado na Figura 3.

Figura 3 - (A) Fotomicrografia da fibra muscular do músculo tibial anterior, em objetiva de $50 x$, com a régua de $100 \mu \mathrm{m}$; (B) - Detalhe das estriações que delimitam os sarcômeros em série.

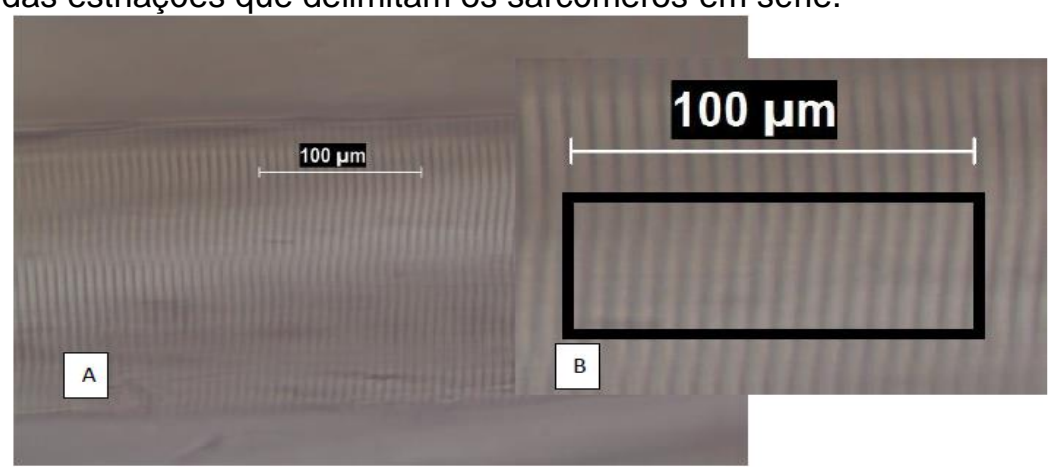

Fonte: Marinho EF, et al., 2018.

Os resultados da pesquisa foram armazenados em planilhas do Microsoft Excel e analisados estatisticamente através de software Bioestatic 5.3. A comparação entre os grupos foi realizada após testes de normalidade com Shapiro Wilk, e para amostras consideradas anormais foi utilizado teste de comparação com Kruskal Wallis + Student, já para as amostras normais foi utilizado o teste ANOVA one-way. Considerando-se um nível de significância de 95,5\% com $p<0,05$. 


\section{RESULTADOS E DISCUSSÃO}

Foi visível a perda de massa corporal dos animais após a utilização do método selecionado para imobilização, uma perda significativa semelhante a encontradas nos estudos de Carvalho CMM (2011), Kodama FY, et al. (2012) e Júnior FFUS, et al. (2010), que destacaram o procedimento de imobilização como um fator estressante, por restringir parcialmente os movimentos e levar a perda ponderal dos animais. Porém, esse dado diferiu dos resultados descritos por Abdalla DR, et al. (2009), que durante 14 dias imobilizaram ratos, mas não encontraram diferença significante entre a massa corporal do início e final da pesquisa. Tal divergência deixa claro que o nível de estresse e as perdas podem variar de acordo com o experimento escolhido.

Neste estudo, as alterações deletérias por desuso nas variáveis macroscópicas de massa e comprimento do músculo foram evidenciadas após a eutanásia, confirmando o decréscimo habitual também observado nas pesquisas de Macedo ACB, et al. (2016) e Ferreira R, et al. (2004).

Para a variável comprimento total do músculo, houve relativo declínio estrutural quanto ao tamanho, seguido de uma sensível melhora com a utilização das terapias propostas. No entanto, a análise estatística demonstrou que não houve significância na comparação entre os grupos, para esta variável com os tratamentos propostos (Gráfico 1).

Gráfico 1 - Comparação entre grupos para a variável comprimento do músculo tibial anterior. Os resultados estão expressos em média, $\mathrm{n}=5 /$ grupo.

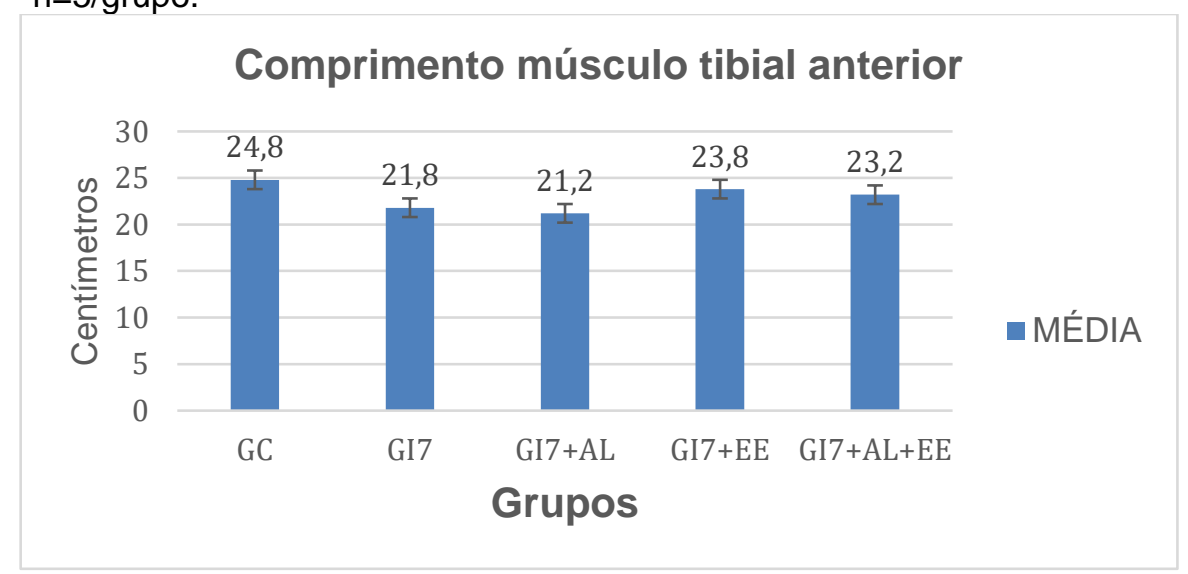

Legenda: $\mathrm{GC}=$ Grupo Controle; GI7 = Grupo Imobilização 7 dias; $\mathrm{Gl7}+\mathrm{AL}=$ Grupo Imobilização 7 dias + alongamento; GI7+EE = Grupo Imobilização 7 dias + eletroestimulação; GI7+AL+EE = Grupo Imobilização 7 dias + alongamento + eletroestimulação. Não houve significância estatística na comparação entre grupos.

Fonte: Marinho, EF, et al., 2018.

Dessa forma, nenhuma terapia demonstrou-se mais eficiente, sobrepondo-se à outra, no que diz respeito à capacidade de causar um aumento significativo quanto ao comprimento total do músculo. Estes resultados divergem dos estudos de Matheus JPC, et al. (2007) e Polonio JT, et al. (2010) que revelaram diferenças significativas em relação ao uso da eletroestimulação - EE, tanto para conter a atrofia quanto para manter o comprimento do músculo.

E também divergem de Rocha WA, et al. (2010), que confirmou o entendimento de outros autores como Gomes ARS, et al. (2004) e Coutinho EL, et al. (2004), que evidenciaram da mesma forma que, o alongamento foi um importante promotor na recuperação do comprimento muscular.

Em relação à variável massa muscular, houve uma perda mensurável durante o período de imobilização por 7 dias. E quando realizada a comparação entre grupos foi possível observar significância estatística entre o resultado do grupo controle $(G C)$ em relação ao grupo que recebeu alongamento passivo (GI7+AL) como tratamento, e entre o grupo controle $(G C)$ e o grupo que recebeu alongamento + eletroestimulação como tratamento $(\mathrm{GI}+\mathrm{AL}+\mathrm{EE})$. 
Também houve significância estatística na comparação entre o grupo que ficou imobilizado por 7 dias (GI7) e o grupo que recebeu alongamento $(G I 7+A L)$ como técnica de tratamento, e entre os grupos imobilizados e tratados com alongamento passivo (GI7+AL) e eletroestimulação (GI7+EE). Conforme é possível observar no (Gráfico 2).

Os resultados apontaram que após 10 sessões de tratamento com as técnicas de alongamento e na associação deste com a eletroestimulação, houve significância estatística entre os grupos que receberam tratamento, mas que estes não representaram ganho de massa muscular comparados a um indivíduo são, pois os valores de massa se demonstraram ainda substancialmente inferiores ao grupo controle. Isso se deve talvez, ao período de tratamento proposto não ter sido compatível com o ciclo de regeneração muscular de 21 a 28 dias.

Raciocínio semelhante podemos associar aos resultados da comparação entre o grupo apenas imobilizado por sete dias e o imobilizado e tratado com alongamento. Justifica-se assim, a necessidade do número de sessões de fisioterapia além do rotineiramente prescrito, com um número superior a 10 sessões diárias, para atuar no mínimo em todo o ciclo de regeneração muscular (GROSSMAN S et al., 2015).

É possível ainda, analisar que a significância estatística encontrada na comparação entre os grupos imobilizados por sete dias e tratados isoladamente, com alongamento (GI7+AL) e eletroestimulação (GI7+EE), se deveu à disparidade do valor médio perdido em miligramas entre os grupos.

Pois foi possível observar que houve ainda uma maior perda de massa no grupo tratado somente com alongamento em comparação ao tratado somente com eletroestimulação, o que corrobora com os estudos de Matheus JPC, et al. (2007) e o mencionado por Agne JE (2009), que revelam o uso da eletroestimulação como maior promotor de ganho de massa, mesmo não sendo possível se observar uma diferença significativa frente ao grupo imobilizado nesse estudo. Assim, a eletroestimulação se demonstrou substancialmente mais eficiente em reduzir a perda total de massa muscular frente ao alongamento.

Gráfico 2 - Comparação entre grupos para a variável massa do músculo tibial anterior. Os resultados estão expressos em média, $n=5 /$ grupo.

\section{Medida de massa do músculo tibial anterior}

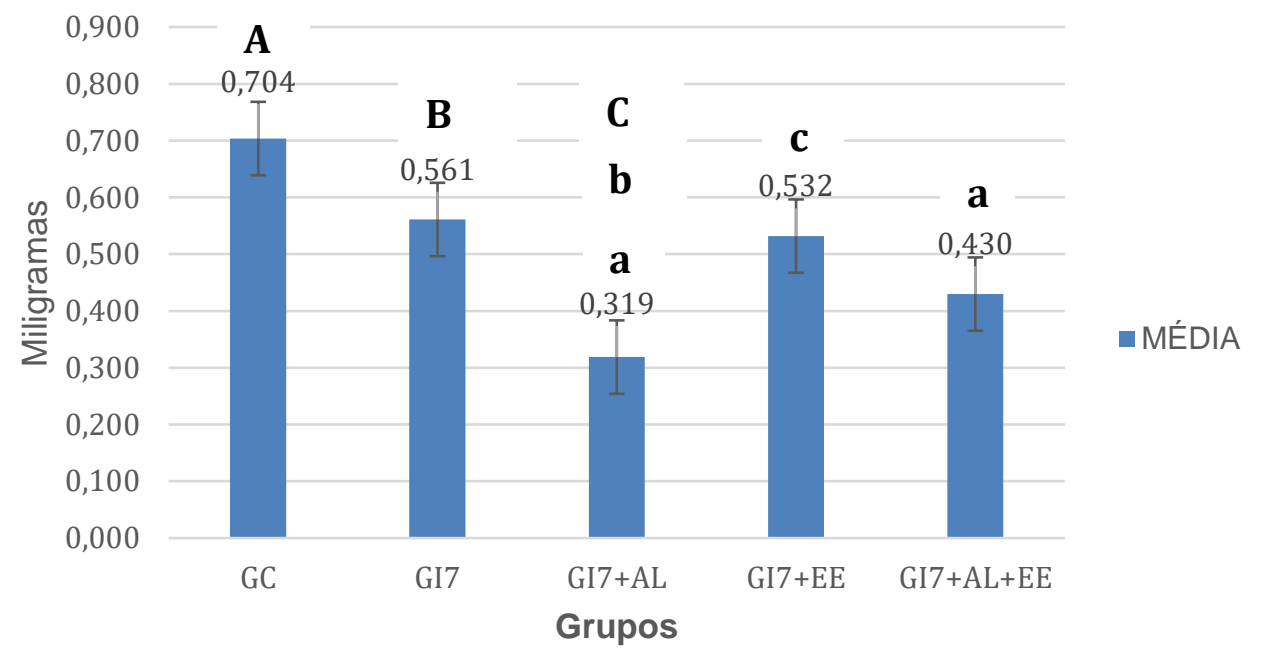

Legenda: $\mathrm{GC}=$ Grupo Controle; GI7 = Grupo Imobilização 7 dias; GI7+AL= Grupo Imobilização 7 dias + alongamento; GI7+EE = Grupo Imobilização 7 dias + eletroestimulação; GI7+AL+EE = Grupo Imobilização 7 dias + alongamento + eletroestimulação.

(A, a) Houve significância estatística na comparação entre GC e Gl7+AL, e entre GC e GI7+AL+EE.

(B, b) Houve significância estatística entre Gl7 e Gl7+AL.

(C, c) Houve significância estatística entre GI7+AL e GI7+EE.

Fonte: Marinho, EF, et al., 2018. 
Os resultados da análise comparativa estatística entre grupos para a variável "número de sarcômeros em série" estão demonstrados no Gráfico 3. E para esta variável, os resultados demonstraram relevância tanto no uso do alongamento (AL) comparado ao grupo controle (GC), quanto da eletroestimulação (EE) em comparação ao grupo apenas imobilizado por 7 dias (GI7). O que demonstrou que as duas terapias de forma isolada foram benéficas para esta variável, porém não foi observada significância estatística entre os resultados encontrados quando da combinação destas terapias na recuperação quanto ao número de sarcômeros em série.

Tal resultado em relação a técnica de alongamento condiz com os achados de Gomes ARS, et al. (2007) e Rocha WA, et al. (2010), que identificaram aumento importante na quantidade de sarcômeros relacionados ao alongamento, porém divergiu de Marques AP (2005) e Agnes JE (2009), que relataram a eletroestimulação como sendo promotora da redução no número de sarcômeros em série devido ao estímulo de contração contínua e prolongada, e não como promotora, como foi observado nesse estudo, no grupo tratado com eletroestimulação após período de imobilização por 7 dias.

Gráfico 3 - Comparação entre grupos para a variável número de sarcômeros em série. Os resultados estão expressos em média, $n=5 /$ grupo.

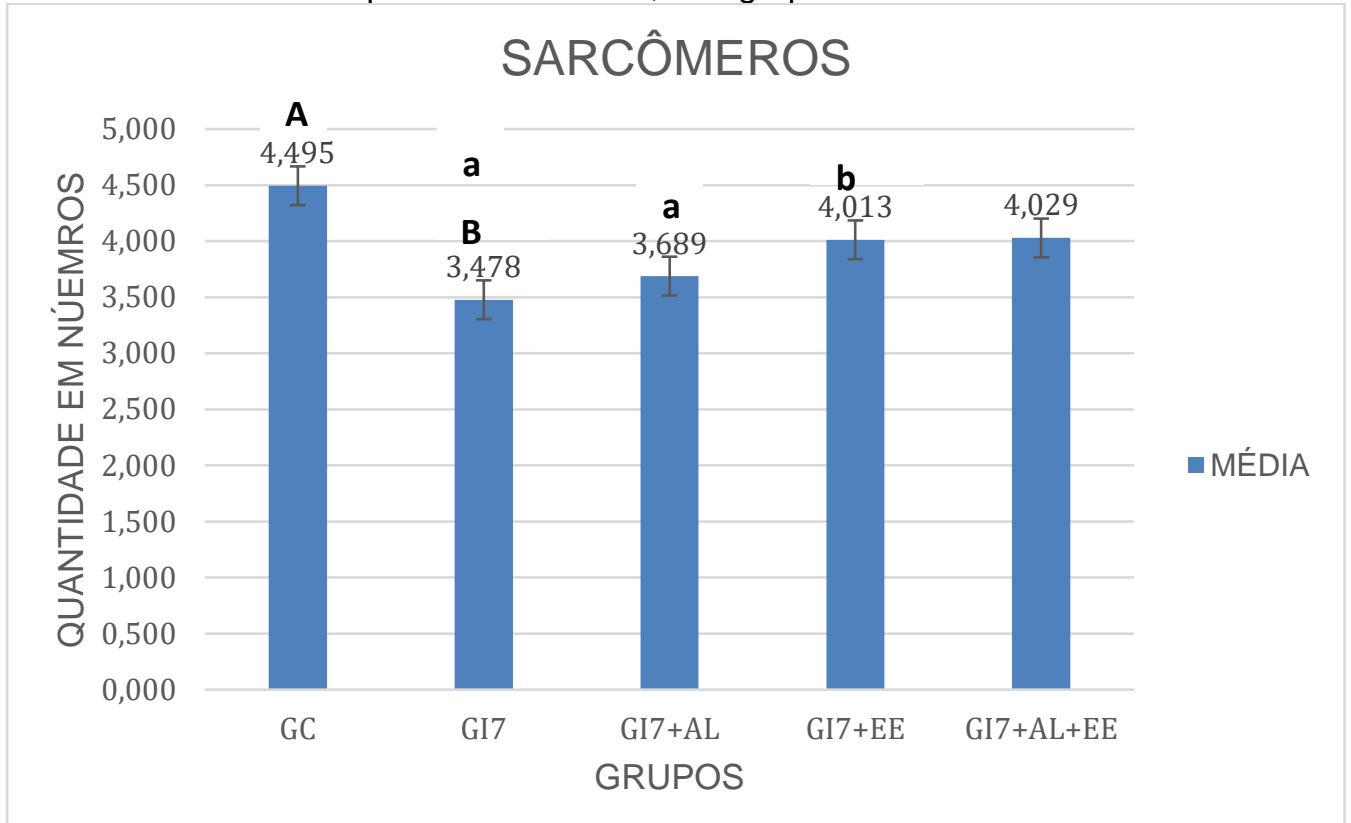

Legenda: $G C=$ Grupo Controle; GI7 = Grupo Imobilização 7 dias; GI7+AL= Grupo Imobilização 7 dias + alongamento; GI7+EE = Grupo Imobilização 7 dias + eletroestimulação; GI7+AL+EE = Grupo Imobilização 7 dias + alongamento + eletroestimulação.

(A, a) Houve significância estatística entre GC e GI7, e GC e GI7+AL.

(B, b) Houve significância estatística entre GI7 e GI7+EE.

Fonte: Marinho, EF, et al., 2018.

A análise qualitativa de forma cega para a deposição de colágeno, quando convertida em dados numéricos, não demonstrou significância entre os grupos, o que foi possível observar no gráfico 4 . Tal resultado diverge do afirmado por Marques AP (2005) e Agnes JE (2009), que indicaram a eletroestimulação como terapia de normalização das atrofias, com remodelação de tecido conjuntivo, e também dos elementos identificados em experimentos como os de Durigan JLQ, et al. (2008) e Rocha WA, et al. (2010), que relacionaram o uso de alongamento ao ganho de comprimento e a hipertrofia muscular.

Podemos relacionar uma diversidade de fatores que influenciariam na composição desses resultados, como as características específicas de determinados músculos, a posição adotada para a imobilização, as variações nas terapias com técnicas e tempos de aplicação diferentes (MATHEUS JPC, et al., 2007; MOORE KL, 2011; POLONIO JT, et al., 2010; MACEDO ACB, et al., 2014; MACEDO ACB, et al., 2016). Além do fato 
de que muitas pesquisas realizam comparações de técnicas que não são usualmente utilizadas, são inviáveis em situações clínicas comuns, ou que só podem ser reproduzidas em nível experimental. Para esta pesquisa buscou-se um protocolo que se aproximasse à prática do Fisioterapeuta, e que pudesse influenciar na escolha ou ampliasse o entendimento do profissional em situações de seu cotidiano. Levantando questionamentos, suscitando discussões e estimulando a continuidade de pesquisas em torno do tema (LIMA SC, et al., 2007; PAIXÃO AP de S, et al., 2011; OSAKI GAT, et al., 2014).

Gráfico 4 - Comparação entre grupos para a variável deposição de colágeno no meio intramuscular. Os resultados estão expressos em média, $n=5 / g r u p o$.

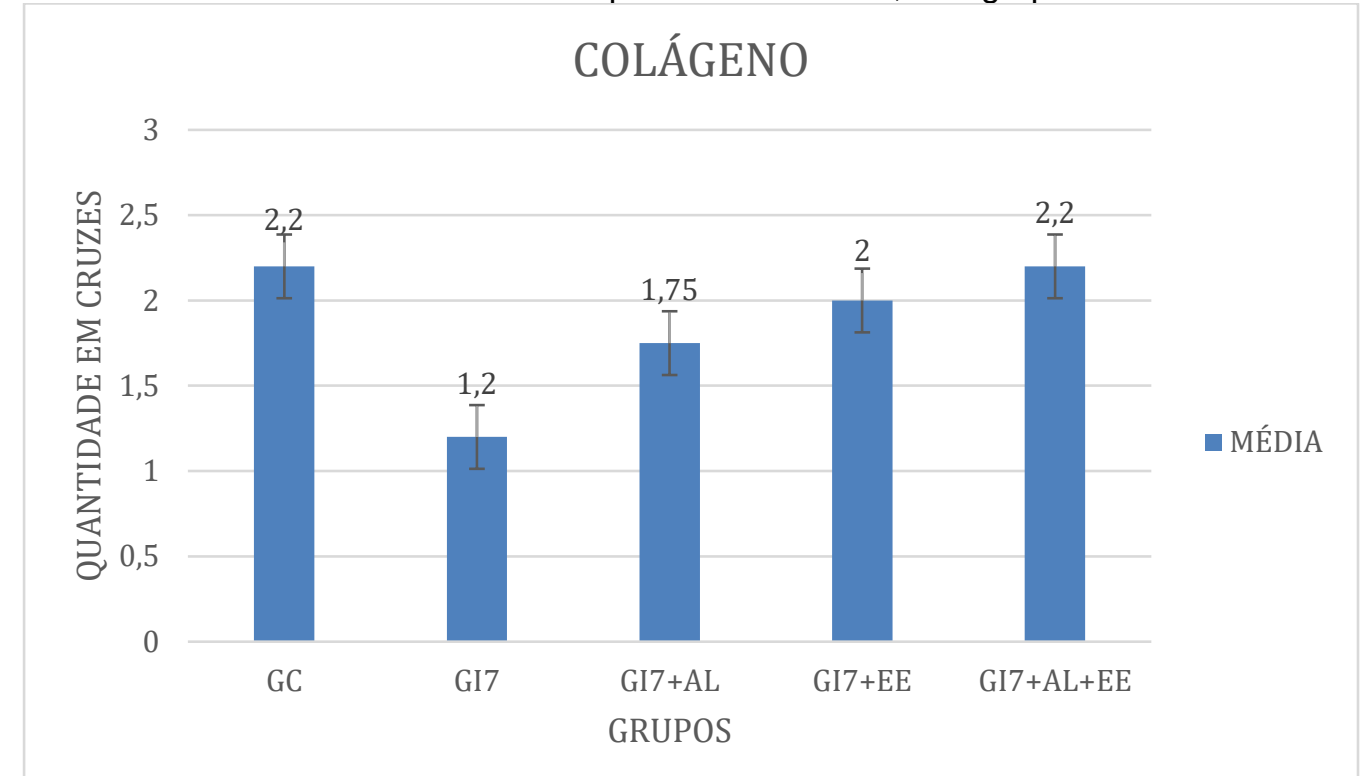

Legenda: $\mathrm{GC}=$ Grupo Controle; GI7 = Grupo Imobilização 7 dias; GI7+AL= Grupo Imobilização 7 dias + alongamento; GI7+EE = Grupo Imobilização 7 dias + eletroestimulação; Gl7+AL+EE = Grupo Imobilização 7 dias + alongamento + eletroestimulação. Não houve significância estatística entre os grupos.

Fonte: Marinho, EF, et al., 2018.

\section{CONCLUSÃO}

Em relação à variável massa muscular, com a metodologia utilizada neste estudo, não foi possível observar ganho de massa sobrepujante à perda pela imobilização, com a utilização das técnicas tanto de forma isolada quanto combinadas. No entanto, observou-se maior eficiência em conter a perda com a utilização da eletroestimulação de forma isolada. Com relação ao número de sarcômeros em série, tanto o alongamento quanto a eletroestimulação muscular apresentaram ganhos estatisticamente relevantes, e a combinação das terapias não representou ganho e nem prejuízo ou interferência no tratamento frente a utilização de forma isolada. Não houve significância estatística entre os grupos de estudo, para as variáveis comprimento do músculo e quantidade de tecido conjuntivo depositado no meio intramuscular. O que demostrou serem essas variáveis indiferentes aos tratamentos utilizados de acordo com o protocolo proposto. É importante salientar a necessidade da continuidade de pesquisas experimentais à cerca do tema, com uniformização dos protocolos de pesquisa utilizados. Dessa forma avançaremos mais rapidamente no entendimento de questões pertinentes e de como utilizar as propriedades plásticas do músculo em terapêuticas cada vez mais eficientes, favorecendo, dessa forma, a padronização das intervenções fisioterapêuticas e trazendo cada vez mais embasamento científico para a prática clínica.

\section{REFERÊNCIAS}

1. ABDALLA DR, et al. Avaliação das propriedades mecânicas do músculo gastrocnêmio de ratas imobilizado e submetido à corrente russa. Fisioterapia e Pesquisa, 2009; 16: 59-64.

2. AGNE JE. Eletrotermoterapia Teoria e Prática. Santa Maria: Orium, 2005; 411p. 
3. AGNE JE. Eu sei eletroterapia. Santa Maria: Palloti, 2009; 399p.

4. AIRES MM. Fisiologia. 5a edição. São Paulo: Guanabara Koogan, 2018; 1.392p.

5. ALTER MJ. Ciência da Flexibilidade. 3a edição. Porto Alegre: Artmed, 2009; 368p.

6. CARVALHO LC, et al. Estimulação elétrica neuromuscular e o alongamento passivo manual na recuperação das propriedades mecânicas do músculo gastrocnêmio imobilizado. Acta Ortopédica Brasileira, 2008; 16: 161-164.

7. CARVALHO CMM. Efeitos da imobilização e do exercício físico em algumas propriedades mecânicas do músculo esquelético. Dissertação (Mestrado Interunidades em Bioengenharia) - EESC/FMRP/IQSC. Universidade de São Paulo, Ribeirão Preto, $2001 ; 73 \mathrm{p}$.

8. COUTINHO EL, et al. Effect of passive stretching on the immobilized soleus muscle fiber morphology. Brazilian Journal of Medical and Biological Research, 2004; 37: 1853-1861.

9. DURIGAN JLQ, et al. Efeitos da estimulação elétrica neuromuscular no músculo sóleo de ratos: análise morfométrica e metabólica. Acta Ortopédica Brasileira, 2008; 16: 4.

10. EGGINTON S, HUDLICKÁ O. Early changes in performance, blood flow and capillary fine structure in rat fast muscles induced by electrical stimulation. J Physiology, 1999; 515:265-75.

11. FERREIRA R, et al. Atrofia muscular esquelética. Modelos experimentais, manifestações teciduais e fisiopatologia. Revista Portuguesa de Ciências do Desporto, 2004; 4: 94-111.

12. FERNANDES F, et al. Atuação fisioterapêutica em imobilismo no leito prolongado. Revista Intellectus, 2011; $10: 25$.

13. GOLDSPINK G, et al. Gene expression in response to muscle stretch. Clin Orthop Relat Res, 2002; 403: 146-152.

14. GOMES ARS, et al. Effects of one stretch a week applied to the immobilized soleus muscle on rat muscle fiber morphology. Braz J Med Biol Res, 2004; 37:1473-80.

15. GOMES ARS, et al. Morphological effects of two protocols of passive stretch over the immobilized rat soleus muscle. J Anat, 2007; 210:328-35.

16. GROSSMAN S et al. Porth: Fisiopatologia. São Paulo: Guanabara Koogan, 2015; 1672p.

17. JÓRZSA L, et al. The effect of tenotomy and immobilization on intramuscular connective tissue. J BONE JOINT SURG, 1990; 72: 293-7.

18. JÚNIOR FFUS, et al. Alterações morfométricas em músculo respiratório de ratos submetidos à imobilização de pata. Rev Bras Med Esporte, 2010; 16 (3): 215-218.

19. KHAJURIA DK, et al. Prophylactic effects of propranolol versus the standard therapy on a new model of disuse osteoporosis in rats. Sci Pharm, 2014; 82: 357-374.

20. KIRSCH RF, et al. Effect of maintained stretch on the range of motion of the human ankle joint. Clinical Biomechanics Oxford, $1985 ; 10$ (3): 166-168.

21. KODAMA FY, et al. Propriedades mecânicas do músculo de ratos adultos e idosos, exercitado pós-imobilização. Acta ortopédica Brasileira, 2012; 20: 4.

22. KONNO E, et al. Remobilização por alongamento estático cíclico em músculo sóleo de ratos imobilizados em encurtamento. Rev Bras Med Esporte, 2008; 14 (2): 122-125.

23. LIMA SC, et al. Curto período de imobilização provoca alterações morfométricas e mecânicas no músculo de rato. Rev. Bras. Fisioter., 2007; 11 (4): 297-302.

24. MACEDO ACB, et al. Efeitos agudos do alongamento muscular do gastrocnêmio após contusão em ratos. Fisioter Pesq, 2014; 21(1):53-59.

25. MACEDO ACB, et al. Estudo morfológico entre diferentes tratamentos da contusão muscular de gastrocnêmio em ratos. Revista Brasileira de Ortopedia, 2016; 51(6): 697-706.

26. MATHEUS JPC, et al. Efeitos da estimulação elétrica neuromuscular durante a imobilização nas propriedades mecânicas do músculo esquelético. Rev Bras Med Esporte, 2007; 13(1): 55-59.

27. MARQUES AP. Cadeias Musculares. Um programa para ensinar Avaliação Fisioterapêutica global. São Paulo: Manole, 2005; $160 \mathrm{p}$.

28. MASSENZ KJV. Efeitos crônicos do exercício de alongamento na histomorfometria e imunomarcação do músculo sóleo de ratas jovens e idosas. Dissertação (Programa de Pós Graduação em Educação Física) - Setor de Ciências Biológicas. Universidade Federal do Paraná, Curitiba, 2019; 111 p.

29. MOORE KL. Anatomia Orientada para a Clínica. 8ed. São Paulo: Guanabara Koogan, 2018; 1128p.

30. OSAKI GAT, et al. Efeitos da remobilização por meio de exercício físico sobre a densidade óssea de ratos adultos e idosos. Motricidade, 2014; 10 (3): 71-78.

31. PAIXÃO AP de $S$, et al. Padronização da técnica de imobilização do membro pélvico para estudo da atrofia muscular esquelética em ratos. Jornal Brasileiro de Ciência Animal, 2011; 4 (7): 274 - 291.

32. POLONIO JT, et al. Eletroestimulação seletiva mantem estrutura e função do tibial anterior desnervado de ratos. Acta Ortop. Bras, 2010; 18(2):85-9.

33. ROCHA WA, et al. Alterações morfofuncionais musculares em resposta ao alongamento passivo em modelo animal de imobilização prolongada de membro posterior. Revista Brasileira de Medicina do Esporte, 2010; 16 (6): 450-454.

34. ROSÁRIO JLR, et al. A. Aspectos clínicos do alongamento: revisão de literatura. Rev. Bras. Fisioter., 2004; 8 1: 83-88.

35. SALVINI TF, et al. Efeitos da eletroestimulação e do alongamento muscular sobre a adaptação do músculo desnervado implicações para a fisioterapia. Rev Bras Fisioter, 2012; 16 (3): 175-83.

36. SMITH LK, et al. Cinesiologia clínica de Brunnstrom. 6a ed. São Paulo: Manole, 2014; 740p.

37. TABARY JC, et al. Physiological and structural changes in the cat's soleus muscle due to immobilization at different lengths by plaster casts. Journal Physiology, 1972; 224: $231-244$.

38. WILLIAMS PE, et al. The importance of strecth and contractile activity in the prevention of connective tissue accumulation in muscle. Journal of Anatomy, 1988; 158: $109-114$.

39. WILLIAMS PE, GOLDSPINK G. Longitudinal growth of striated muscle fibres. J Cell Sci, 1971; 9(3): 751-67. 